\title{
Reliability Enhancement and Loss Reduction in Radial Distribution System by Reconfiguration using BFA
}

\author{
E. R. Biju \\ Lecturer \\ Department of Electrical and Electronics Engineering \\ Government Polytechnic College \\ Nagercoil, India
}

\begin{abstract}
This paper presents a new methodology to solve radial distribution system (RDS) reconfiguration problem to reduce the losses and to enhance the reliability of the system. Optimal reconfiguration selects the best set of feeders by changing the switching status of sectionalizing and tie switches so that the resulting RDS has improved voltage profile and minimum power loss. In addition, the impact of DG and capacitor are also considered in the problem formulation. Also in order to calculate the reliability indices such as SAIFI, SAIDI, CAIDI, AENS and ASAI, the reconfiguration technique is considered as a failure rate reduction strategy. This paper presents the application of bacterial foraging algorithm (BFA) to solve optimal network reconfiguration problem. A standard IEEE 69 bus radial system is chosen for the study. To show the effectiveness of the proposed algorithm in finding the best solution, simulations are carried out on the test system and the results are briefly compared before and after reconfiguration.
\end{abstract}

\section{Keywords}

Distributed generator, Reconfiguration, Reliability indices, Bacterial foraging algorithm, Radial distribution system.

\section{INTRODUCTION}

An electrical distribution network consists of a group of interconnected radial networks. The configuration of RDS may be varied via switching operations to transfer loads among the feeders. In RDS, there are two types of switches; sectionalizing-switches (normally closed) and tie-switches (normally open) [1]. The reconfiguration of the distribution system is a process of opening sectionalizing switches and closing tie switches so that the radial structure of the network is maintained and all of the loads are supported. This results in balancing system load, reduced power losses, improved bus voltage profile and system reliability. The complexity of the reconfiguration problem increases as the circuit elements are switched in and out, certain variables tracking their status assume discrete values and because of the discontinuous nature of solution space. Hence it becomes difficult to solve this problem by conventional linear/nonlinear programming methods. In the past decades, a number of investigations has been carried out on reconfiguration problem. In order to minimize active power loss and voltage deviation, heuristic techniques [2], expert systems [3], brute-force approach [4], harmony search algorithm [5], evolution programming [6] have been proposed.

Capacitors are widely used in distribution networks for the purpose of reactive power compensation which results in good voltage profile. In the literature, some researchers have considered reconfiguration and capacitor placement problems simultaneously. They have used methods such as branch exchange [7], ACSA [8], modified PSO [9 and 24], deterministic approach [10] etc to solve reconfiguration problem and methods like discrete optimization [11], harmony search algorithm [5], heuristic technique [12], Imperialist Competitive Algorithm [25] Adaptive Shuffled Frogs Leaping Algorithm [26] etc to determine the optimal location and amount of capacitances to be used.

In recent years, penetration of distributed generations (DG) in the RDS has been increased widely. This increase can be justified by the factors such as environmental concerns, the restructuring of electricity market and the development in technologies for small-scale generation. If DGs are correctly installed at optimal locations and its units are correctly coordinated, they will reduce power losses in distribution system.

In the literature, many researchers have attempted to determine the optimum location and size of DG units in the distribution system. In-Su et al [13] described an analytical method to determine the reliability of a distribution system with DG. They considered three modes of operations of DG such as stand by unit, peaking unit and mixed mode operation. Gozel et al [14] determined optimal allocation and sizing of DGs using an analytical method in view of minimum line loss. Venkatesh et al [15] focus on the aspects of loss minimization and voltage enhancement of RDS by artificial intelligence methods. Rashidi et al [16] were presented an improved PSO for optimal placement of multiple DG sources to minimize real power losses. Kang et al [17] proposed a novel efficient population-based heuristic approach. Hamedi et al [18] were presented an innovative approach to increase reliability and reducing power loss with optimal placement of DG resources in an actual distribution network.

This paper emphasizes the advantage of reconfiguration of RDS in the presence of DG and capacitor for loss reduction, bus voltage improvement and reliability enhancement. The bacterial foraging algorithm is used to solve the reconfiguration problem with DG and capacitor. Standard IEEE 69 bus radial distribution system is considered as test system. Expected interruption cost (ECOST) corresponding to interruption duration time is calculated using composite customer damage function (CCDF). This system is further analyzed to show the increasing reliability levels as suggested by the improvements in various reliability indices such as SAIFI, SAIDI, CAIDI and AENS. 


\section{RELIABILITY ANALYSIS OF DISTRIBUTION SYSTEM}

Reliability analysis of electrical distribution system is considered as a tool for the planning engineer to ensure a reasonable quality of service and to choose between different system expansion plans that cost wise were comparable considering system investment and cost of losses. The usual method of evaluating the reliability indices is an analytical approach which based on failure mode assessment and the use of equations for series and parallel networks. The analytical approach is based on assumptions concerned with statistical distributions of failure rates and repair times. The common indices used for evaluation are the expected failure rate $(\lambda)$, the average outage time (r) and the expected annual outage times (U) which is adequate to the sample radial system. The basic reliability indices of the system are given by:

$\lambda_{s y s, i}=\sum_{k \in s} \lambda_{k}$

$U_{s y s, i}=\sum_{k \in s} \lambda_{k} r_{k}$

Where $\lambda_{\mathrm{k}}$, and $\mathrm{r}_{\mathrm{k}}$ are the average failure rate and average outage time of the $\mathrm{i}^{\text {th }}$ component respectively.

In this paper, expected interruption cost (ECOST) is included as part of the objective function. Evaluating ECOST enables the system planners to determine the acceptable level of reliability for customers, provided economic justifications for determining network reinforcement and redundancy allocation, identify weak points in a system, determine suitable maintenance scheduling and develop appropriate operation policies. ECOST is therefore a powerful tool for system planning [19]. ECOST at bus $\mathrm{i}$ is calculated as follows:

$$
E \operatorname{COST}_{i}=\sum_{i=1} L_{a(i)} C_{i} \lambda_{i}
$$

Where $\mathrm{L}_{\mathrm{a}(\mathrm{i})}$ is the average load connected to load point $\mathrm{i}$ in $\mathrm{kW}$ and $\mathrm{C}_{\mathrm{i}}$ is the cost of interruption (in $\$ / \mathrm{kw}$ ) for the $\mathrm{i}^{\text {th }}$ bus.

The total ECOST of the distribution feeder is calculated as follows:

$$
E \operatorname{COST}=\sum_{i=1}^{N B} E \operatorname{COS} T_{i}=\sum_{i=1}^{N B} L_{a(i)} C_{i} \lambda_{i}
$$

Where NB is the total number of load points in the feeder. In order to submit the importance of a system outage, energy not supplied index (ENS) is evaluated. This index reflects total energy not supplied by the system due to faults during study period and is calculated for each load bus i using the following equation:

$E N S_{i}=L_{a(i)} U_{i}$

A customer damage function (CDF) provides the interruption cost versus interruption duration for a specified group of customers. The CCDF is basically the sum of the individual customer damage functions in the customer mix. The sector customer damage function (SCDF) of the residential, commercial and industrial sectors etc. can be combined to create a composite customer damage function (CCDF). CCDF shows the cost of interruption as a function of interruption duration. A typical CCDF [19] is illustrated in Fig 1. Since it accounts for reliability worth and the reliability level, ECOST is a comprehensive value based reliability index and was used for this study.

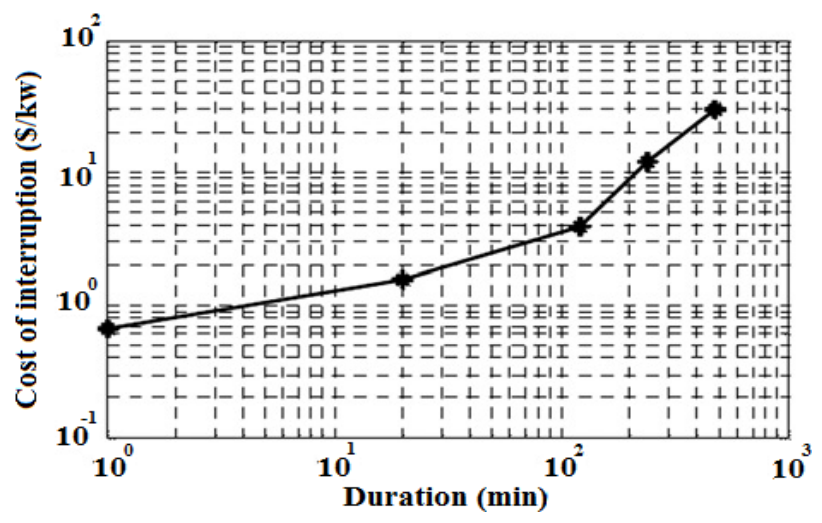

Fig 1: Typical CCDF

\section{DISTRIBUTION SYSTEM RELIABILITY ENHANCEMENT USING DG AND CAPACITOR}

Majority of the customer interruptions are caused by equipment failures in distribution systems consisting of underground cables and overhead lines. Resistive losses increase the temperature of feeders which is proportional to the square of the current magnitude flowing through the feeder. Moreover increase in temperature causes insulation failure in underground cable and overhead lines which in turn increases the component failure rate. If DG and capacitors are installed at appropriate places, they can supply part of active and reactive power demands respectively. This reduces the resistive losses due to reduction of the magnitude of current. These impacts on reliability are taken into consideration as a failure rate reduction of distribution feeder components.

Let us assume that any feeder i has an uncompensated failure rate of $\lambda_{i}^{\text {uncomp }}$ before DG and capacitor placement. If the reactive or active component of a feeder branch is fully compensated, its failure rate reduces to $\lambda_{i}^{\text {comp }}$. If the reactive and active components of current are not completely compensated, a failure rate is defined with linear relationship to the percentage of compensation. Thus, the compensation coefficient of the $\mathrm{i}^{\text {th }}$ branch is defined as:

$$
\alpha_{i}=\frac{I_{r}^{\text {new }}}{I_{r}^{\text {old }}} * \frac{I_{a}^{\text {new }}}{I_{a}^{\text {old }}}
$$

Where $\mathrm{I}_{\mathrm{r}}{ }^{\text {new }}, \mathrm{I}_{\mathrm{r}}^{\text {old }}$ and $\mathrm{I}_{\mathrm{a}}^{\text {new }}, \mathrm{I}_{\mathrm{a}}{ }^{\text {old }}$ are the reactive and active components of the $i^{\text {th }}$ branch current after and before compensation, respectively. The new failure rate of the $i^{\text {th }}$ branch is computed as follows:

$$
\lambda_{i-n e w}=\alpha_{i}\left(\lambda_{i}^{\text {uncomp }}-\lambda_{i}^{\text {comp }}\right)+\lambda_{i}^{\text {comp }}
$$

\section{CUSTOMER-BASED RELIABILITY INDICES}

A survey by Electric Power Research Institute (EPRI) has identified the most frequently used customer oriented indices are namely SAIFI, SAIDI, CAIDI, AENS and ASAI. These indices are defined as follows [20]. 
4.1 System Average Interruption Frequency Index (SAIFI):

$$
\begin{aligned}
\text { SAIFI } & =\frac{\text { Total numbers of customer int erruptions }}{\text { Total number of customers served }} \\
& =\frac{\sum \lambda_{\mathrm{sys} \mathrm{i}} \mathrm{N}_{\mathrm{i}}}{\sum \mathrm{N}_{\mathrm{i}}}
\end{aligned}
$$

\subsection{System Average Interruption Duration Index (SAIDI):}

$$
\begin{aligned}
\text { SAIDI } & =\frac{\text { Sum of all customer int erruptions durations }}{\text { Total number of customer served }} \\
& =\frac{\sum \mathrm{U}_{\mathrm{sys} \mathrm{i}} \mathrm{N}_{\mathrm{i}}}{\sum \mathrm{N}_{\mathrm{i}}}
\end{aligned}
$$

\subsection{Customer Average Interruption} Duration Index (CAIDI):

$$
\begin{aligned}
\text { CAIDI } & =\frac{\text { Sum of all customer int erruption durations }}{\text { Total number of customer int erruptions }} \\
= & \frac{\sum \mathrm{U}_{\mathrm{sys} \mathrm{s}} \mathrm{N}_{\mathrm{i}}}{\sum \lambda_{\mathrm{sys} \mathrm{i}} \mathrm{N}_{\mathrm{i}}}
\end{aligned}
$$

\subsection{Average Energy Not Supplied (AENS):}

$$
A E N S=\frac{\text { Sumof system annual outage duration at load point }}{\text { Sumof average load point }}
$$$$
=\frac{\sum \mathrm{L}_{\mathrm{i}} \mathrm{U}_{\text {sysi }}}{\sum \mathrm{N}_{\mathrm{i}}}
$$

\subsection{Average Service Availability Index} (ASAI):

$$
\begin{aligned}
\text { ASAI }= & \frac{\text { Ccustomer hours service availability }}{\text { Customer hours servisedemand }} \\
& =[(8760-\mathrm{SAIDI}) / 8760]^{*} 100
\end{aligned}
$$

Where $L_{i}$ is average load connected at $i^{\text {th }}$ load point, which may be obtained from load duration curve, $\lambda_{\text {sys, } i}$ is the system failure rate at ${ }^{\text {th }}$ load point, $\mathrm{N}_{\mathrm{i}}$ is total number of customers at load point $i$ and $U_{s y s, i}$ is system annual outage duration at $i^{\text {th }}$ load point.

\section{PROBLEM FORMULATION}

The main objective of this paper is to determine the optimal location and size of DG and capacitor in distribution systems in order to improve the system reliability and to reduce the power loss along with minimum installation cost of DG and capacitor. Losses in the distribution feeders and voltage of all nodes are found by backward - forward sweep distribution load flow analysis. In this paper a multi objective function is considered on the basis of active power loss index, reliability index, voltage profile index and DG and capacitor investment cost index which are defined as follows:

\subsection{Multiobjective Function}

The multiobjective function of the problem is described as:

$$
\begin{gathered}
\text { Mininize } \quad J=\sum_{m=1}^{4} K_{m} J_{m} \\
K_{m} \in[0,1], \sum_{m=1}^{4} K_{m}=1
\end{gathered}
$$

Where, $\mathrm{k}_{\mathrm{m}}$ are weighting factors assigned to each objectives are $K_{1}=0.4, K_{2}=0.1, K_{3}=0.1$ and $\mathrm{K}_{4}=0.4$ attributed to power loss, reliability, voltage deviation and DG's and Capacitor's Investment Cost Index, respectively.

\subsection{Real Power Loss Index $\left(J_{1}\right)$}

Power losses are important factor in the design of distribution systems and are calculated by backward - forward sweep load flow method in radial distribution system. At a given time, the power loss index is given by

$J_{1}=\frac{P_{L, D G \& c a p}}{P_{L}}$

Where $\mathrm{P}_{\mathrm{L}, \mathrm{DG} \& \mathrm{Cap}}$ is the total real power loss of the distribution system in the presence of DG and capacitor and $\mathrm{P}_{\mathrm{L}}$ is the total real power loss without DG and capacitor in the distribution system.

\subsection{Reliability Index $\left(\mathbf{J}_{2}\right)$}

Reliability index is given by

$$
J_{2}=\frac{E C O S T_{D G \& c a p}}{E C O S T}
$$

Where Ecost ${ }_{\text {DG\&Cap }}$ and Ecost is expected interruption cost of system with and without DG and capacitor installation, respectively.

\subsection{Voltage deviation index $\left(J_{3}\right)$}

Bus voltage is one of the most important characteristic of the system. One of the benefits of correct selection of location and size of DG and capacitor is improvement of voltage deviation. This index indicates higher voltage deviations from 1.0 per unit. Voltage deviation index (VDI) is expressed as

$$
J_{3}=\sum_{i=1}^{N B}\left|V_{i}-1\right|
$$

where NB is total number of the buses, $V_{i}$ is the magnitude voltage on the $\mathrm{i}^{\text {th }}$ bus.

\subsection{DG's and Capacitor's Investment Cost Index $\left(\mathbf{J}_{4}\right)$}

DG and capacitor are appropriate selections for minimizing both the line loss and improving the network reliability and voltage profile. However, the investment cost of DG and capacitor is a significant problem that prevents engineers using them widely. This index is calculated with the following equation:

$J_{4}=\frac{\operatorname{Cost}_{D G}}{\operatorname{Cost}_{M C D}}+\frac{\operatorname{Cost}_{c a p}}{\operatorname{Cost}_{M C C}}$ 
where Cost $_{\mathrm{DG}}$ and Cost $_{\text {Cap }}$ are costs of DG and capacitor, respectively. Cost $_{\mathrm{MCD}}$ and Cost $_{\mathrm{MCC}}$ are costs of DG and capacitor in their maximum capacity, respectively.

\section{BACTERIAL FORAGING ALGORITHM}

BFA is an optimization method developed by Kevin M. Passino [21], based on the foraging strategy of Escherichia Coli (E. Coli) bacteria that live in the human intestine. Foraging strategy is a method of animals for locating, handling and ingesting their food. The foraging strategy of E.Coli is governed basically by four processes namely chemotaxis, swarming, reproduction, elimination and dispersal.

\subsection{Chemotaxis}

Chemotaxis process is the characteristics of movement of bacteria in search of food and consists of two processes namely swimming and tumbling. A bacterium is said to be 'swimming' if it moves in a predefined direction, and 'tumbling' if moving in an altogether different direction. Let $\mathrm{j}$ be the index of chemotactic step, $\mathrm{k}$ be the reproduction step and 1 be the elimination dispersal event. Let $\theta^{\mathrm{i}}(\mathrm{j}, \mathrm{k}, \mathrm{l})$ is the position of $\mathrm{i}^{\text {th }}$ bacteria at $\mathrm{j}^{\text {th }}$ chemotactic step, $\mathrm{k}^{\text {th }}$ reproduction step and $1^{\text {th }}$ elimination dispersal event. The position of the bacteria in the next chemotactic step after a tumble is given by

$\theta^{i}(j+1, k, l)=\theta^{i}(j, k, l)+C(i) * \frac{\Delta(i)}{\sqrt{\Delta^{T}(i) * \Delta(i)}}$

If the health of the bacteria improves after the tumble, the bacteria will continue to swim in the same direction for the specified steps or until the health degrades.

\subsection{Swarming}

Bacteria exhibits swarm behavior i.e. healthy bacteria try to attract other bacteria so that together they reach the desired location (solution point) more rapidly. The effect of Swarming is to make the bacteria congregate into groups and move as concentric patterns with high bacterial density.

$$
\begin{aligned}
& J_{c c}(\theta, P(j, k, l))=\sum_{i=1}^{n} J_{c c}\left(\theta, \theta^{i}(j, k, l)\right) \\
& =\sum_{i=1}^{s}\left[-d_{\text {attract }} \exp \left(-W_{\text {attract }} \sum_{i=1}^{n}\left(\theta_{m}-\theta_{m}^{i}\right)^{2}\right)\right]+ \\
& \sum_{i=1}^{s}\left[-d_{\text {repellant }} \exp \left(-W_{\text {repellant }} \sum_{i=1}^{n}\left(\theta_{m}-\theta_{m}^{i}\right)^{2}\right)\right]
\end{aligned}
$$

\subsection{Reproduction}

In this step, population members who have had sufficient nutrients will reproduce and the least healthy bacteria will die. The healthier half of the population replaces with the other half of bacteria which gets eliminated, owing to their poorer foraging abilities. This makes the population of bacteria constant in the evolution process.

\subsection{Elimination and Dispersal}

Gradual or sudden changes in the local environment where a bacterium population lives may occur due to various reasons e.g. a significant local rise of temperature may kill a group of bacteria that are currently in a region with a high concentration of nutrient gradients. Events can take place in such a fashion that all the bacteria in a region are killed or a group is dispersed into a new location. To simulate this phenomenon in BFA some bacteria are liquidated at random with a very small probability while the new replacements are randomly initialized over the search space.

\section{SIMULATION RESULTS AND DISCUSSION}

Optimal reconfiguration, capacitor and DG placement in optimal locations are performed using the proposed BF algorithm on standard IEEE 69 bus RDS in view of loss reduction and voltage and reliability enhancement. The test system is a radial distribution network with rated voltage of $12.66 \mathrm{KV}, 100 \mathrm{MVA}, 69$ nodes, 74 lines, 5 contact switches and the total load is $3802.2 \mathrm{KW}+\mathrm{j} 2694.6 \mathrm{KVAr}$. The test system is shown in figure 2 . The test system details are found in [22].

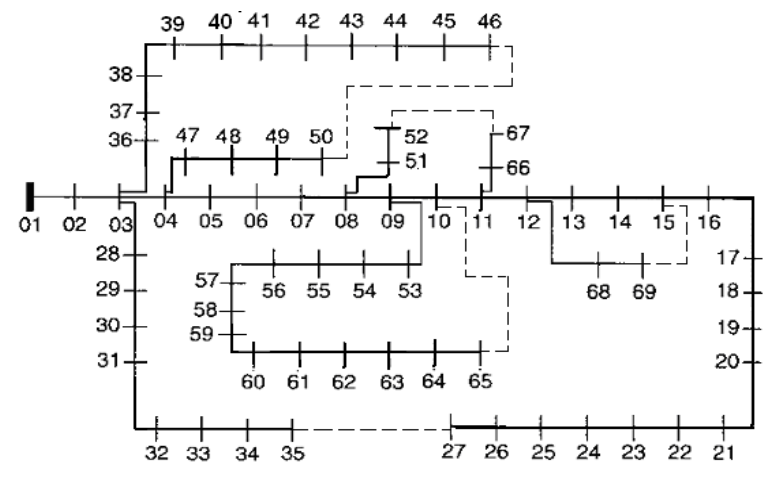

Fig 2: IEEE 69 bus system

It is assumed that the section with the highest resistance has the biggest failure rate of $0.5 \mathrm{f} / \mathrm{year}$ and the section with the smallest resistance has the least failure rate of $0.1 \mathrm{f} /$ year. Based on this assumption, failure rates of other sections are calculated linearly proportional to these two values according to their resistances.

Furthermore, it is assumed that if the reactive or active component of a distributor section current is fully compensated, its failure rate reduces to $85 \%$ of its uncompensated failure rate [23] and for partial compensation, the failure rate is calculated using (7). In this paper, some assumptions are made to evaluate the reliability indices. It is assumed that there is a circuit breaker (CB) at the substation with a sectionalizer at the beginning of each section. Since the reconfiguration strategy only affects the reliability of the feeders, the other network components, such as the transformers, busbars, and sectionalizer switches, are supposed to be fully reliable. Besides, for each line, the repair time and total isolation and switching time are considered as 8 hours and 0.5 hours respectively.

The following bacterial foraging algorithm parameters, $S$ (10), $\mathrm{N}_{\mathrm{c}}(20), \mathrm{N}_{\mathrm{s}}(12), \mathrm{N}_{\mathrm{re}}(10)$ and $\mathrm{N}_{\mathrm{ed}}$ (5) are considered for simulation. Component failure rate is optimized using the compensation coefficient (7) which in turn used to calculate the customer reliability indices i.e. SAIFI, SAIDI, CAIDI, AENS and ASAI before and after reconfiguration [20]. The available DG and Capacitor sizes and their associated cost are given in table 1. Simulations were carried out on $1.86 \mathrm{GHz}$ system in MATLAB 7.5 version environment. 
Table 1. DG and capacitor size and costs

\begin{tabular}{|l|l|l|l|}
\hline \multicolumn{2}{|c|}{ DG } & \multicolumn{2}{c|}{ Capacitor } \\
\hline $\begin{array}{l}\text { Size } \\
(\text { KW })\end{array}$ & Cost (\$) & $\begin{array}{l}\text { Size } \\
\text { (KVAr) }\end{array}$ & Cost $\mathbf{\$})$ \\
\hline 250 & 2121 & 150 & 750 \\
\hline 500 & 1500 & 300 & 975 \\
\hline 750 & 1225 & 450 & 1140 \\
\hline 1000 & 1061 & 600 & 1320 \\
\hline 1250 & 949 & 900 & 1650 \\
\hline 1500 & 866 & 1200 & 2040 \\
\hline 1750 & 802 & & \\
\hline 2000 & 750 & & \\
\hline
\end{tabular}

The following case studies are carried out for reliability enhancement of the radial distribution system.

Case A: Before reconfiguration

1. With DG alone

2. With Capacitor alone

3. With DG and Capacitor

The topology of test system is considered as such and BF algorithm is used to find the optimum location and size of DG and capacitor by minimizing the multiobjective function given in equation (13). Table 2 gives optimum location and size of
DG and capacitor obtained using proposed method. Table 3 gives the ECOST, ENS, $\mathrm{P}_{\text {LOSS }}$, $\mathrm{Q}_{\text {LOSS, }}$ VDI and minimum voltage magnitude obtained using the $\mathrm{BF}$ algorithm. In this table, base case represents the system without DG and capacitor. In order to show the impact of DG and capacitor, the results are compared with base case. \% improvement achieved by the bacterial foraging algorithm compared with that of base case is also given in table 3 . Fig 3 shows voltage profiles in each bus of test system before reconfiguration with DG and capacitor. Fig 4 shows line loss in each segment of the distribution system before reconfiguration with DG and capacitor.

Table 2. Optimal size and location of DG and Capacitor before reconfiguration

\begin{tabular}{|c|c|c|}
\hline \multirow{2}{*}{} & \multicolumn{2}{|c|}{ Before reconfiguration } \\
\cline { 2 - 3 } & Installed at & $\begin{array}{c}\text { Size } \\
\text { (KW/KVAr) }\end{array}$ \\
\hline DG & 58 & 1500 \\
\hline Capacitor & 61 & 450 \\
\hline DG and & 21 & 500 \\
Capacitor & 63 & 600 \\
\hline
\end{tabular}

Table 3. Results obtained before reconfiguration

\begin{tabular}{|c|c|c|c|c|c|c|}
\hline & $\begin{array}{c}\text { ECOST } \\
\mathbf{( \$ )}\end{array}$ & $\begin{array}{c}\text { ENS } \\
(\mathbf{K W h} / \mathbf{y r})\end{array}$ & $\begin{array}{c}\mathbf{P}_{\text {Loss }} \\
\mathbf{( K W )}\end{array}$ & $\begin{array}{c}\mathbf{Q}_{\text {Loss }} \\
\mathbf{K V A r})\end{array}$ & $\begin{array}{c}\text { VDI } \\
(\mathbf{p . u})\end{array}$ & $\begin{array}{c}\text { Minimum } \\
\text { voltage } \\
\text { magnitud } \\
\mathbf{e}(\mathbf{p . u})\end{array}$ \\
\hline Base case & 117646.37 & 15713.97 & 226.59 & 104.42 & 1.843 & 0.9092 \\
\hline With DG & 98781.43 & 12456.54 & 187.23 & 99.07 & 0.935 & 0.9321 \\
\hline $\begin{array}{c}\text { With } \\
\text { capacitor }\end{array}$ & 75231.20 & 9304.28 & 201.41 & 71.03 & 1.531 & 0.9235 \\
\hline $\begin{array}{c}\text { With DG } \\
\text { and } \\
\text { capacitor }\end{array}$ & 41064.25 & 6268.16 & 153.79 & 61.25 & 0.844 & 0.9373 \\
\hline $\begin{array}{c}\text { \% of } \\
\text { improve } \\
\text { ment }\end{array}$ & 65.09 & 60.11 & 32.12 & 41.34 & 54.20 & 3.09 \\
\hline
\end{tabular}

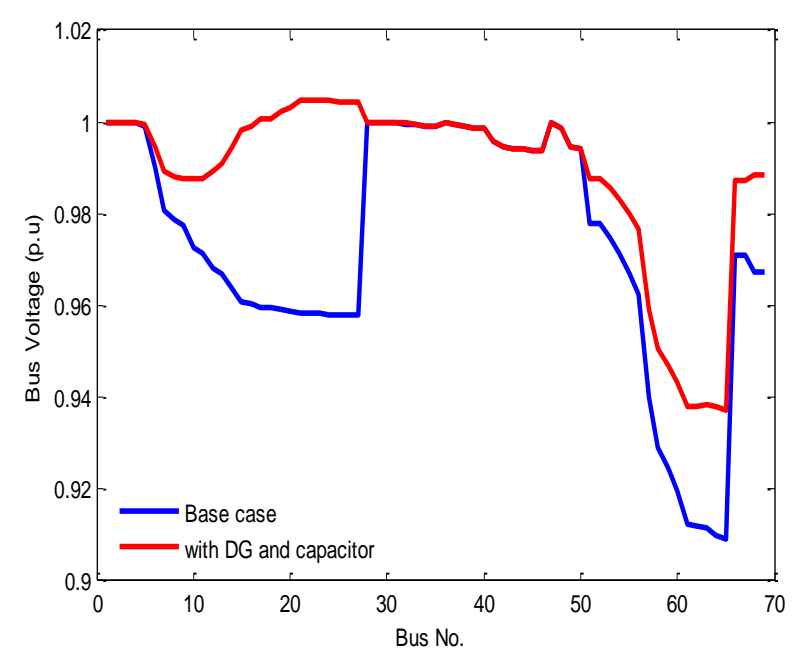

Fig 3:Voltage profile in each bus before reconfiguration

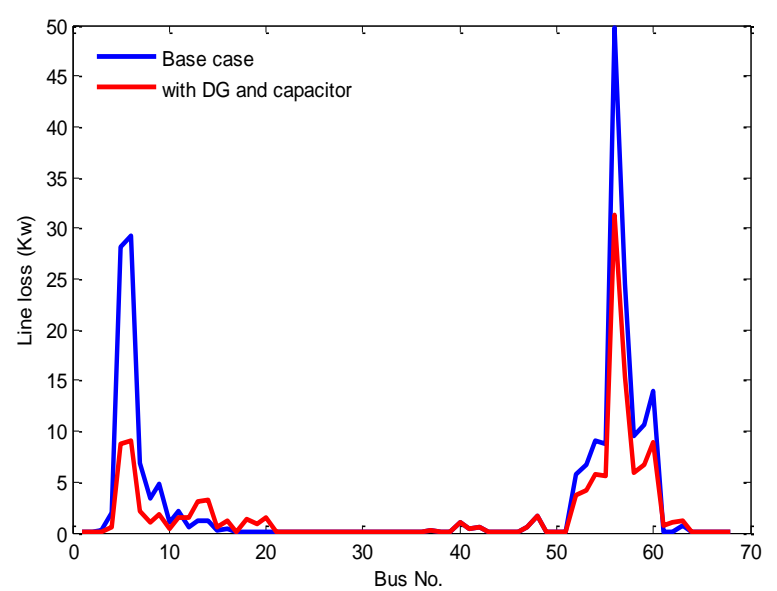

Fig 4: Line loss in each branch before reconfiguration 
Case B: After reconfiguration

1. With DG alone

2. With Capacitor alone

3. With DG and Capacitor

The reconfiguration is done on standard IEEE 69 bus distribution system. Table 4 shows the open switches in the system corresponding to before and after reconfiguration. Opening and closing of switches can change the amount of power loss which can be seen in Table 4. This shows the validity and effectiveness achieved due to reconfiguration of

RDS using proposed method.

Table 4. Results of simulation for test on 69-bus system

\begin{tabular}{|c|c|c|c|}
\hline \multicolumn{2}{|c|}{ Scenario } & Base case & $\begin{array}{l}\text { Optimal case } \\
\text { (with DG } \\
\text { and } \\
\text { capacitor) }\end{array}$ \\
\hline \multicolumn{2}{|c|}{ Open switches } & $\begin{array}{c}69,70,71, \\
72,73\end{array}$ & $\begin{array}{c}26,50,65 \\
70,72\end{array}$ \\
\hline \multirow{2}{*}{$\begin{array}{c}\text { Before } \\
\text { Reconfiguration }\end{array}$} & $\begin{array}{c}\mathbf{P}_{\text {Loss }} \\
(\mathbf{K W})\end{array}$ & 226.59 & 153.79 \\
\hline & $\begin{array}{c}\text { Q }_{\text {Loss }} \\
\text { (KVAr) }\end{array}$ & 104.42 & 61.25 \\
\hline \multirow{2}{*}{$\begin{array}{c}\text { After } \\
\text { Reconfiguration }\end{array}$} & $\begin{array}{l}\mathbf{P}_{\text {Loss }} \\
(\mathbf{K W})\end{array}$ & 175.01 & 93.03 \\
\hline & $\begin{array}{c}\text { Q }_{\text {Loss }} \\
\text { (KVAr) }\end{array}$ & 85.61 & 54.21 \\
\hline
\end{tabular}

Table 5. Optimal size and location of DG and Capacitor after reconfiguration

\begin{tabular}{|c|c|c|}
\hline \multirow{2}{*}{} & \multicolumn{2}{|c|}{ After reconfiguration } \\
\cline { 2 - 3 } & Installed at & $\begin{array}{c}\text { Size } \\
\text { (KW/KVAr) }\end{array}$ \\
\hline DG & 59 & 1250 \\
\hline Capacitor & 61 & 900 \\
\hline DG and & 9 & 750 \\
Capacitor & 12 & 450 \\
\hline
\end{tabular}

Table 6. Results obtained after reconfiguration.

\begin{tabular}{|c|c|c|c|c|c|c|}
\hline & $\begin{array}{c}\text { ECOST } \\
(\$)\end{array}$ & $\begin{array}{c}\text { ENS } \\
(\mathbf{K W h} / \mathbf{y} \\
\mathbf{r})\end{array}$ & $\begin{array}{c}\mathbf{P}_{\text {Loss }} \\
\mathbf{( K W )}\end{array}$ & $\begin{array}{c}\mathbf{Q}_{\text {Loss }} \\
\mathbf{K V} \\
\mathbf{A r})\end{array}$ & $\begin{array}{c}\text { VDI } \\
(\mathbf{p . u})\end{array}$ & $\begin{array}{c}\mathbf{V}_{\text {min }} \\
(\mathbf{p . u})\end{array}$ \\
\hline Base case & 113981.56 & $\begin{array}{c}14237.3 \\
1\end{array}$ & 175.01 & 85.61 & $\begin{array}{c}1.76 \\
8\end{array}$ & 0.9127 \\
\hline With DG & 98176.00 & $\begin{array}{c}12205.7 \\
1\end{array}$ & 152.32 & 79.43 & $\begin{array}{c}1.27 \\
8\end{array}$ & 0.9413 \\
\hline $\begin{array}{c}\text { With } \\
\text { capacitor }\end{array}$ & 70810.39 & 8784.53 & 163.45 & 68.67 & $\begin{array}{c}1.10 \\
2\end{array}$ & 0.9392 \\
\hline $\begin{array}{c}\text { With DG } \\
\text { and } \\
\text { capacitor }\end{array}$ & 38343.19 & 5342.90 & 93.03 & 54.21 & $\begin{array}{c}0.97 \\
8\end{array}$ & 0.9354 \\
\hline $\begin{array}{c}\text { \% of } \\
\text { improvemen } \\
\mathbf{t}\end{array}$ & 66.36 & 62.47 & 46.84 & 36.67 & $\begin{array}{c}44.6 \\
8\end{array}$ & 2.48 \\
\hline
\end{tabular}

Table 5 gives optimum location and size of DG and capacitor obtained using proposed method after reconfiguration. Table 6 gives the ECOST, ENS, $\mathrm{P}_{\text {LOSS }}$, $\mathrm{Q}_{\text {Loss }}$, VDI and minimum voltage magnitude obtained using the $\mathrm{BF}$ algorithm. In this table, base case represents the system without DG and capacitor after reconfiguration. \% improvement achieved using bacterial foraging algorithm by placing DG and capacitor in optimal locations is determined in comparison with the base case and is also given in the table 6 .

It may be noted from tables 3 and 5 that there is an improvement of $6.62 \%$ in ECOST, $14.76 \%$ in ENS, $39.50 \%$ in $\mathrm{P}_{\mathrm{LOSS}}, 11.4 \%$ in $\mathrm{Q}_{\mathrm{LOSS}}, 15.8 \%$ in VDI and $0.20 \%$ in voltage magnitude compared with before and after reconfiguration. This clearly shows the impact of reconfiguration of the RDS Fig 5 shows voltage profiles in each bus of test system after reconfiguration. Fig 6 shows line loss in each branch of the system after reconfiguration.

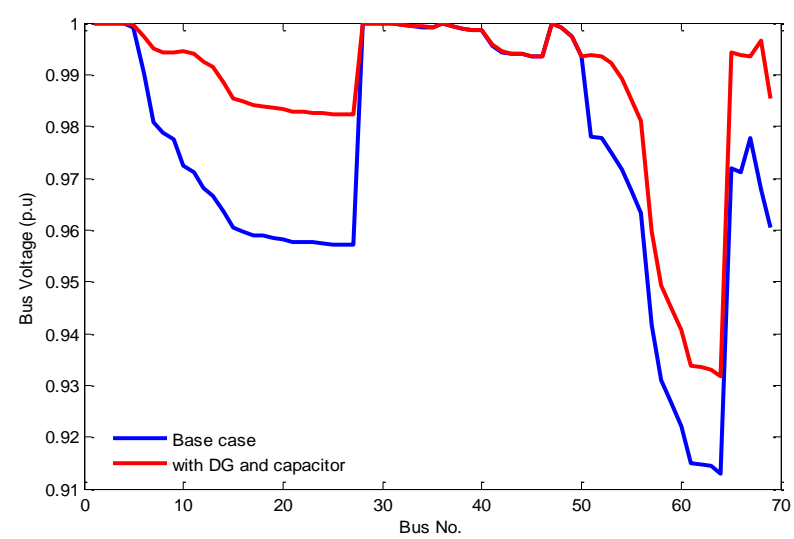

Fig 5: Voltage profile in each bus after reconfiguration

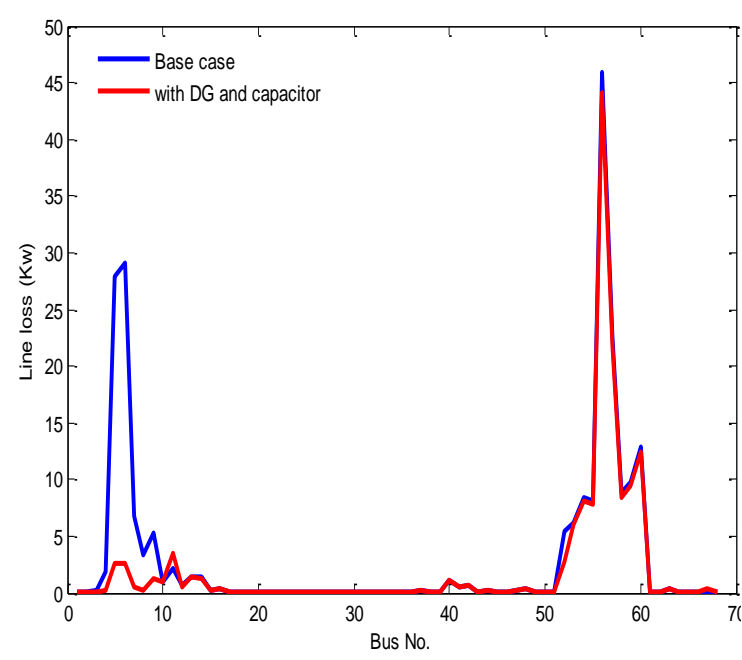

Fig 6: Line loss in each branch after reconfiguration

Further, the customer and energy based load point reliability indices for 69 bus test system before and after reconfiguration are also calculated using optimized failure rate and are given in table 7 and table 8 respectively. 
Table 7. Customer and energy based reliability indices for 69 bus test system before reconfiguration

\begin{tabular}{|c|c|c|c|c|}
\hline \multicolumn{5}{|c|}{ Before Reconfiguration } \\
\hline & $\begin{array}{c}\text { Base } \\
\text { case }\end{array}$ & $\begin{array}{c}\text { With } \\
\text { DG }\end{array}$ & $\begin{array}{c}\text { With } \\
\text { Capacitor }\end{array}$ & $\begin{array}{c}\text { With DG } \\
\text { \& } \\
\text { Capacitor }\end{array}$ \\
\hline SAIFI & 2.5896 & 1.4960 & 1.5956 & 1.1451 \\
\hline SAIDI & 1.9824 & 0.8060 & 0.8595 & 0.8426 \\
\hline CAIDI & 0.7655 & 0.5347 & 0.5387 & 0.7358 \\
\hline AENS & 0.4197 & 0.1624 & 0.1837 & 0.1822 \\
\hline ASAI & 99.974 & 99.990 & 99.9902 & 99.9904 \\
\hline
\end{tabular}

Table 8. Customer and energy based reliability indices for 69 bus test system after reconfiguration

\begin{tabular}{|c|c|c|c|c|}
\hline \multicolumn{5}{|c|}{ After Reconfiguration } \\
\hline & $\begin{array}{c}\text { Base } \\
\text { case }\end{array}$ & $\begin{array}{c}\text { With } \\
\text { DG } \\
\text { Capacitor }\end{array}$ & $\begin{array}{c}\text { With DG } \\
\text { \& } \\
\text { capacitor }\end{array}$ \\
\hline SAIFI & 2.5257 & 2.5015 & 1.3693 & 1.9925 \\
\hline SAIDI & 1.9853 & 1.9663 & 0.9051 & 1.6944 \\
\hline CAIDI & 0.7857 & 0.7861 & 0.6610 & 0.8504 \\
\hline AENS & 0.4162 & 0.4121 & 0.1853 & 0.3512 \\
\hline ASAI & 99.977 & 99.9776 & 99.989 & 99.980 \\
\hline
\end{tabular}

\section{CONCULSION}

In this paper, the bacterial foraging algorithm optimization technique has been used to find the most appropriate topology of the distribution system in the presence of DG and Capacitor in view of loss minimization and reliability improvement. The proposed algorithm has been applied on the standard IEEE 69 bus distribution system. Better results are obtained after reconfiguration of RDS. Finally the energy and customer based reliability indices were evaluated using the optimized failure rates and repair times of the distributor segments. It is seen that reliability indices are also improved and voltage profile of all the buses remained stable within the tolerable limits. Real and reactive power losses are also reduced and hence reliability is improved.

\section{REFERENCES}

[1] Mesut E. Baran and Felix F. Wu, 1989. "Network reconfiguration in distribution systems for loss reduction and load balancing", IEEE Transactions on Power Delivery, Vol. 4, No. 2.

[2] T. Taylor and D. Lubkeman, 1990. "Implementation of heuristic search strategies for distribution feeder reconfiguration", IEEE Transactions on Power Delivery, Vol.5, No.3, pp.239-245.

[3] D. Shirmohammadi and H. W. Hong, 1989. "Reconfiguration of electrical distribution networks for resistive line loss reduction", IEEE Transactions on Power Systems, Vol. 4, No. 2, pp. 1492-1498.
[4] A. B. Morton and I. M. Y. Mareels, 2000. "An efficient brute-force approach solution to the network reconfiguration problem", IEEE Transactions on Power Delivery, Vol. 15, No. 3, pp. 996-1000.

[5] R. Srinivasa Rao, S. V. L. Narasimham, M. Ramalinga Raju, and A. Srinivasa Rao, 2011. "Optimal network reconfiguration of large-scale distribution system using harmony search algorithm", IEEE Transactions on Power Systems, Vol. 26, No. 3, pp. 1080-1088.

[6] Y. T. Hsiao, 2004. "Mutiobjective evolution programming method for feeder reconfiguration", IEEE Transactions on Power Systems, Vol. 19, No. 1, pp. 594 599.

[7] G. J. Peponis, M. P. Papadopulos and N. D. Hatziargyriou, 1996. "Optimal operation of distribution networks", IEEE Transactions on Power Systems, Vol 11, No. 1, pp. 59-67.

[8] C. F. Chang, 2008. "Reconfiguration and capacitor placement for loss reduction of distribution systems by ant colony search algorithm", IEEE Transactions on Power Systems, Vol. 23, No.4, pp. 1747-1755.

[9] P. Rezaei and M. Vakilian, 2010. "Distribution system efficiency improvement by reconfiguration and capacitor placement using a modified particle swarm optimization algorithm", IEEE Electrical Power and Energy Conference, Halifax, pp. 1-6.

[10] D. P. Montoya and J. M. Ramirez, 2012 "Reconfiguration and optimal capacitor placement for losses reduction", IEEE/PES, Transmission and Distribution: Latin America Conference and Exposition, Montevideo, Piscataway, pp. 1-6.

[11] J. Dan and R. Baldick, 1996. "Optimal electric distribution system switch reconfiguration and capacitor control", IEEE Transactions on Power Systems, Vol. 11, No.2, pp. 890-897.

[12] P. Rezaei, M. Vakilian and E. Hajipour, 2011. "Reconfiguration and capacitor placement in radial distribution systems for loss reduction and reliability enhancement", $16^{\text {th }}$ International Conference on Intelligent System Application to Power Systems, Hersonissos, Piscatawa, pp. 1-6.

[13] In-Su Bae and Jin-O Kim, 2007. "Reliability evaluation of distributed generation based on operation mode," IEEE Transactions on Power Systems, Vol. 22, No. 2, pp. $785-790$.

[14] T. Gozel and M. H. Hocaoglu, 2009. "An analytical method for the sizing and siting of distributed generators in radial systems," Electric Power Systems Research, Vol. 79, No. 6, pp. 912-918.

[15] B. Venkantesh, S. Chandramohan, N. Kanyavizhi and R. P. Kumudini Devi, 2009. "Optimal reconfiguration of radial distribution system using artificial intelligence methods" IEEE Toronto international conference, Toronto, ON, pp.660-665.

[16] M. R. Rashidi and M. F. Hajri, 2011. "Optimal planning of multiple distributed generation sources in distribution networks: A new approach", Energy Conversion and Management, Vol. 52, No. 11, pp. 3301-3308. 
[17] Q. Kang, T. Lan, Y. Yan, L. Wang and Q. Wu, 2012. "Group search optimizer based optimal location and capacity of distributed generations", Journal Neurocomputing, Vol.78, No.1, pp.55-63.

[18] H. Hamedi and M. Gandomkar, 2012. "A straightforward approach to minimizing unsupplied energy and power loss through DG placement and evaluating power quality in relation to load variations over time", Electrical Power and Energy Systems, Vol.35, No.1, pp. 93-96.

[19] L. Goel, R. Billinton, 1991. "Evaluation of interrupted energy assessment rates in distribution systems", IEEE Transaction on Power Delivery, Vol. 6, No.4, pp.1876 1882.

[20] R. Billinton, and R. N Allan, 1996. "Reliability evaluation of power systems", Springer International Edition.

[21] B. Kevin and M. Passino, 2002. "Biomimicry of bacterial foraging for distributed optimization and control", IEEE Control System Magazine, Vol. 22, No. 3, pp. 52- 67.

[22] Abdollah Kavousi-Fard and Taher Niknam, 2014. "Optimal distribution feeder reconfiguration for reliability improvement considering uncertainty", IEEE Transaction on Power Delivery, Vol. 29, No. 3, pp. 1344-1353.
[23] Zahra Boor and Seyyed Mehdi Hosseini, 2013. "GA based optimal placement of DGs for loss reduction and reliability improvement in distribution networks with time varying loads", International Journal of Intelligent Systems and Applications, Vol. 5, No. 4, pp. 55-63.

[24] Su Mon Myint and Soe Win Naing, 2015. "Network reconfiguration for loss reduction and voltage stability improvement of 74-bus radial distribution system using particle swarm optimization algorithm" International Journal of Electrical, Electronics and Data Communication, Vol. 3, No. 6, pp.32-38.

[25] M. Sedighizadeh M. Esmaili and M. M. Mahmoodi, 2017. "Reconfiguration of Distribution Systems to Improve Reliability and Reduce Power Losses using Imperialist Competitive Algorithm", Iranian Journal of Electrical \& Electronic Engineering, Vol. 13, No. 3, pp. 287-302.

[26] Arun Onlam, Daranpob Yodphet, Rongrit Chatthaworn, Chayada Surawanitkun, Apirat Siritaratiwat and Pirat Khunkitti, 2019. "Power Loss Minimization and Voltage Stability Improvement in Electrical Distribution System via Network Reconfiguration and Distributed Generation Placement Using Novel Adaptive Shuffled Frogs Leaping Algorithm www.mdpi.com/journal/energies, pp.4-12. 